\title{
LETTERS
}

\section{Is referral necessary for abnormal bleeding?}

The suggestion by Drs. Sholzberg, Teitel and Hicks that patients be referred to their specialities (hematology and pathobiology) for work-up of abnormal bleeding in the presence of a positive screening questionnaire or family history is frustrating. ${ }^{1}$

The authors fail to acknowledge the skill of family physicians and the ability of local laboratories to implement best practices to allow patients to stay in their home communities without costing the system thousands in travel and having to leave their work and families. Instead, it would be better to see these physicians suggesting what blood tests need to be done and understanding that family physicians can forward the results, rather than the patient, to them for diagnosis.
As a family physician who works in remote communities, I understand that workups for von Willebrand disease have been compromised by transport conditions in the past, but I suggest that these physicians look more deeply into the scope of family physicians and local laboratories.

I'll even put in the intrauterine device without having to refer the patient.

\section{Sarah M. Giles MD}

Family physician, locum physician

Cite as: CMAJ 2017 November 6;189:

E1368. doi: 10.1503/cmaj.733352

\section{Reference}

1. Sholzberg M, Teitel J, Hicks LK. A 24-year-old woman with heavy menstrual bleeding. CMAJ 2017;189:E779-80.

Competing interests: None declared. 